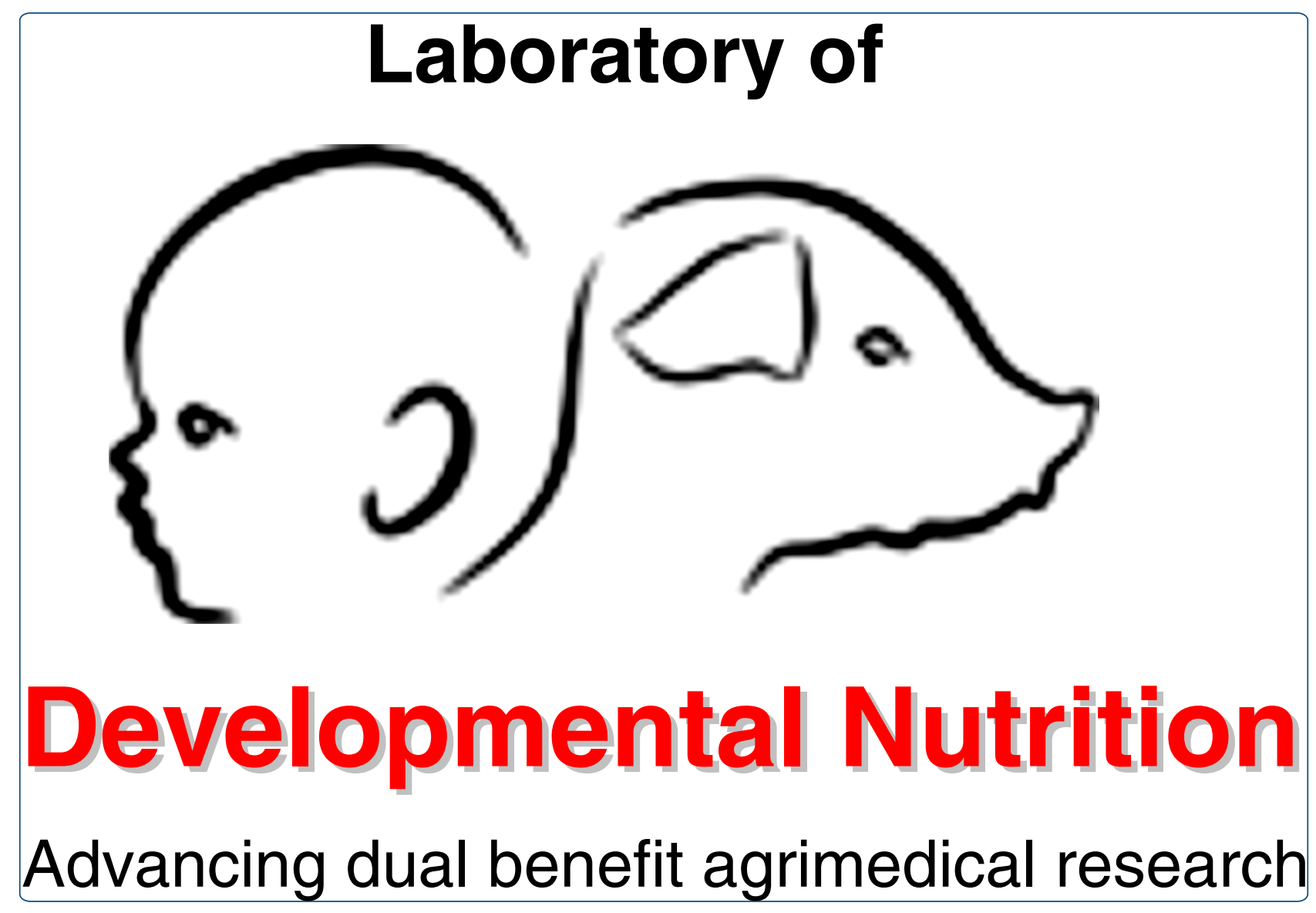

The effect of 5-aminoimidazole-4-carboxamide ribonucleoside (AICAR) on fatty acid oxidation in hepatocytes isolated from neonatal piglets Xi et al. 


\title{
The effect of 5-aminoimidazole-4-carboxamide ribonucleoside (AICAR) on fatty acid oxidation in hepatocytes isolated from neonatal piglets
}

Lin $\mathrm{Xi}^{1^{*}}$, Gary Matsey ${ }^{1,2}$ and Jack Odle

\begin{abstract}
In the present study, the effect of 5-aminoimidazole-4-carboxamide ribonucleoside (AICAR) on long-chain fatty acid oxidation by hepatocytes isolated from suckled neonatal pig liver (a low ketogenic and lipogenic tissue) was tested. Incubation of hepatocytes with AICAR $(0.5 \mathrm{mM})$ in the presence of $1 \mathrm{mM}$ of carnitine and $10 \mathrm{mM}$ of glucose for 1 hour at $37^{\circ} \mathrm{C}$ had no significant effect on total $\left[1-{ }^{14} \mathrm{C}\right]$-palmitate $(0.5 \mathrm{mM})$ oxidation $\left({ }^{14} \mathrm{CO}_{2}\right.$ and ${ }^{14} \mathrm{C}$-Acid soluble products (ASP)). Consistent with the fatty acid oxidation, carnitine palmitoyltransferase I activity and inhibition of its activity by malonyl-CoA $(10 \mu \mathrm{M})$ assayed in cell homogenate also remained constant. However, addition of AICAR to the hepatocytes decreased ${ }^{14} \mathrm{CO}_{2}$ production by $18 \%$ compared to control $(\mathrm{p}<0.06)$. The reduction of labeled carboxylic carbon accumulated in $\mathrm{CO}_{2}$ caused a significant difference in distribution of oxidative products between ${ }^{14} \mathrm{CO}_{2}$ and ${ }^{14} \mathrm{C}$-ASP $(\mathrm{p}<0.03)$ compared with the control. It was also noticed that acetyl-CoA carboxylase (ACC) was increased by AICAR $(p<0.03)$, indicating that ACC might drive acetyl-CoA toward fatty acid synthesis pathway and induce an increase in distribution of fatty acid carbon to ${ }^{14} \mathrm{C}$-ASP. Addition of insulin to hepatocyte incubations with AICAR did not change the oxidative product distribution between $\mathrm{CO}_{2}$ and ASP, but further promoted ACC activity. The increased ACC activity was 70\% higher than in the control group when citrate was absent in the reaction medium and was 30\% higher when citrate was present in the medium. Our results suggest that AICAR may affect the distribution of metabolic products from fatty acid oxidation by changing ACC activity in hepatocyte isolated from suckled neonatal piglets; however, the basis for the increase in ACC activity elicited by AICAR is not apparent.
\end{abstract}

Keywords: Suckled neonatal pig, 5-aminoimidazole-4-carboxamide ribonucleoside (AICAR), Carnitine palmitoyltransferase (CPT), Acetyl-CoA carboxylase (ACC)

\section{Background}

The carnitine palmitoyltransferase (CPT) enzyme system is among the most important sites of regulation of hepatic long-chain fatty acid oxidation. Studies with fasted and diabetic animals have shown that the rise in fatty acid oxidation is mainly controlled by a decrease in malonyl-CoA concentration, a potent inhibitor of CPT I, and/or by a decrease in sensitivity of CPT I to the inhibition by malonyl-CoA (see Figure 1). A similar control mechanism also is found in neonatal rats and rabbits during the first 24 hours of life. In contrast, the role of

\footnotetext{
*Correspondence: lin_xi@ncsu.edu

'Laboratory of Developmental Nutrition, Department of Animal Science, North Carolina State University, Raleigh, NC 27695, USA

Full list of author information is available at the end of the article
}

CPT I in the regulation of fatty acid metabolism in neonatal piglets is not understood completely and displays interesting differences. The rate of long-chain fatty acid oxidation in liver mitochondria isolated from $24 \mathrm{~h}$-old fasted pigs showed only a mild increase over newborns which was 70\% lower than that observed in fasted adult rats. However, CPT I activity in pig liver mitochondria doubled between birth and 24 hour of age, and liver malonyl-CoA levels were very low due to a low hepatic lipogenesis in neonatal piglets. Duée et al. [1] reported that CPT I in neonatal pig liver was 50 times more sensitive than that from fasted adult rats. Studies from our laboratory [2-4] showed that the rate of long-chain fatty acid oxidation in hepatocytes, liver homogenates and mitochondria from neonatal piglets could be altered by 


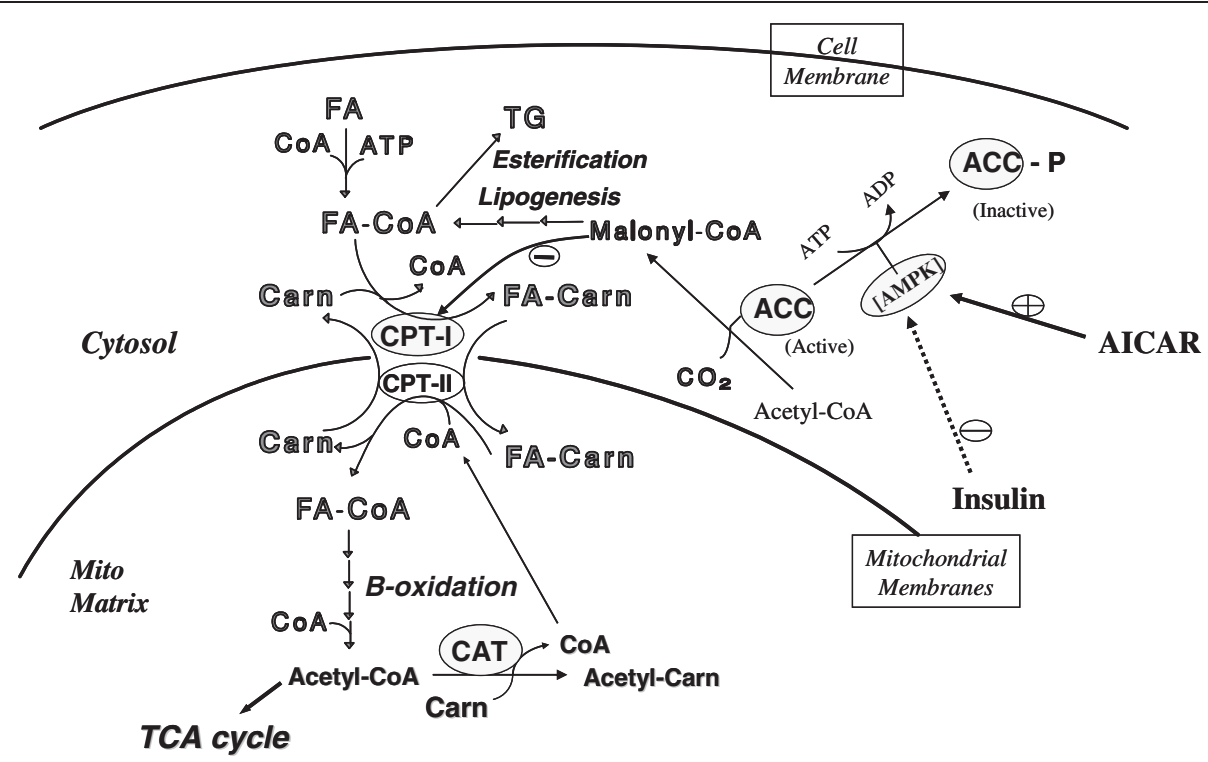

Figure 1 Key roles of CPT I and ACC in fatty acid metabolism. FA - Fatty acid, TG - Triglycerides, Carn - Carnitine, CPT - carnitine palmitoyltransferase, ACC - acetyl-CoA carboxylase, and AICAR - 5-aminoimidazole-4-carboxamide ribonucleoside.

changes in activity of CPT. The changes in CPT I activity, however, was not attributable to an increase in CPT I gene expression, but rather to a large decrease in the sensitivity of CPT I to malonyl-CoA inhibition. Moreover, the increase in fatty acid oxidation caused by the decrease of CPT I sensitivity to malonyl-CoA inhibition after birth is associated with food intake, emphasizing the importance of food intake in the regulation of fatty acid oxidation during early development. Because the pig CPT I protein is identified to be a natural chimera of the more typical mammalian liver and muscle CPT I isotypes, containing the liver CPT I binding site for acyl$\mathrm{CoA}$ and the muscle CPT I binding sites for carnitine and malonyl-CoA, we have been interested in the role of malonyl-CoA in the kinetic modulation of hepatic CPT I in the 24-h old fed piglets.

Malonyl-CoA, as the physiological inhibitor of CPT I, is the product of acetyl-CoA carboxylase (ACC). The activity of ACC plays a very important role in regulating carbohydrate and fatty acid metabolism, specifically the $\alpha$ isoform in lipogenic tissues and the $\beta$ isoform, with a mitochondrial leader sequence, in non-lipogenic tissues [5]. The activity of ACC is controlled via a cycle of phosphorylation-dephosphorylation. The mechanism of interconversion of ACC from an active dephosphorylated form into a less active phosphorylated form as well as the hormonal control of ACC has been studied extensively during the past years. It is currently accepted that in intact hepatocytes and in the liver in vivo, the phosphorylation of ACC is mainly performed by a protein kinase termed the 5-adenosine monophosphate-activated protein kinase (AMPK). Studies indicated that insulin activates ACC in the liver through a dephosphorylation mechanism involving inhibition of AMPK, while the stimulation of AMPK inhibits fatty acid and cholesterol synthesis (Figure 1). 5-aminoimidazole-4-carboxamide ribonucleoside (AICAR) has been reported to be a specific activator of AMPK in intact cells. The effects of AICAR on fatty acid metabolism were tested in intact heart, muscle and liver cells [6-8]. It also was observed that a two-fold stimulation of palmitate oxidation and CPT activity occurred in hepatocytes isolated from rats incubated with AICAR along with a significant decrease in ACC activity and malonyl-CoA levels [9]. A recent study indicated that the AICAR increases mRNA expression of peroxisome proliferator-activated receptor (PPAR $\alpha)$ target genes and peroxisome proliferator-activated receptor- $\gamma$ coactivator (PGC)- 1 in cultured muscle cells and mouse skeletal muscle [10]. There is limited information regarding hepatic ACC in swine particularly in neonatal pigs. To investigate the role of ACC in the regulation of fatty acid oxidation via a change of malonyl-CoA concentration, in this study we examined the effect of AICAR on fatty acid oxidation by hepatocytes isolated from suckled neonatal pigs.

\section{Methods}

Animal and hepatocyte isolation

All procedures were approved by the Institutional Animal Care and Use Committee of North Carolina State University. A total five suckled neonatal piglets (32 hold, $1400 \pm 200 \mathrm{~g}$ ) from five sows were obtained from NCSU research farm unit II and hepatocytes were isolated using a two stage collagenase perfusion technique 
as described previously [11]. The cell yields were counted as $\sim 1.75 \times 10^{9}$ per liver and viability (Trypan Blue exclusion) was about 95\% using this method. Cell and cell homogenate proteins were determined using biuret method [12].

\section{Hepatocyte incubation}

After isolation cells (approximately $75 \mathrm{mg}$ protein $/ \mathrm{mL}$ ) were incubated in Krebs-Henseleit bicarbonate buffer containing $10 \mathrm{mM}$ glucose, $1 \mathrm{mM}$ carnitine, and $3 \%(\mathrm{w} / \mathrm{v})$ defatted BSA with different supplementations (I. $0.5 \mathrm{mM}$ AICAR [9], II. $10 \mathrm{mU} / \mathrm{mL}$ insulin, and III. $0.5 \mathrm{mM}$ AICAR plus $10 \mathrm{mU} / \mathrm{ml}$ insulin) and without supplementation (IV. control). Incubation was performed in 125-mL flasks at $37^{\circ} \mathrm{C}$ for 20 minutes with constant shaking under an atmosphere of $\mathrm{O}_{2} / \mathrm{CO}_{2}$ (19:1). Fatty acid oxidation and enzyme assays were performed either in the hepatocytes or hepatocyte homogenates after incubation.

\section{Fatty acid oxidation}

For determination of fatty acid oxidation, $2.5 \mathrm{~mL}$ of incubation cells from each treatment in triplicate were transferred into $25-\mathrm{mL}$ flasks. Subsequently, the reaction was started by addition of $3 \mu$ moles of $\left[1-{ }^{14} \mathrm{C}\right]$-palmitate $(0.15 \mu \mathrm{Ci} / \mu \mathrm{mol})$ bound to BSA (3\%) in $0.5 \mathrm{~mL}$ of KrebsHenseleit bicarbonate buffer. The reaction was continued as described above for 30 minutes and stopped by addition of $0.5 \mathrm{~mL}$ of $\mathrm{HClO}_{4}(30 \%, \mathrm{vol} / \mathrm{vol})$. The accumulation of $\left[1-{ }^{14} \mathrm{C}\right]$ in $\mathrm{CO}_{2}$ and acid soluble products (ASP) was measured using the techniques as described by Odle et al. [11]. The total oxidation rate was calculated as sum of $\mathrm{CO}_{2}$ and ASP.

\section{Enzyme assays}

Hepatocytes $(10 \mathrm{~mL})$ were transferred into centrifuge tubes after incubation (total 50 minutes) and centrifuged at $50 \mathrm{x} \mathrm{g}$ for 3 minutes. The resultant cell pellet was homogenized in a buffer containing mannitol (220 mM), sucrose $(70 \mathrm{mM})$, HEPES $(2 \mathrm{mM})$ and EDTA $(0.1 \mathrm{mM})$ using a glass-homogenizer with 3 strokes. The homogenate was used for the enzyme analysis directly as follows:

Malonyl-CoA sensitive CPT activity was measured using the method of Bremer et al. [13] slightly modified by our laboratory [14]. The assay was conducted at $37^{\circ} \mathrm{C}$ in a buffer containing $\mathrm{KCl}(75 \mathrm{mM})$, mannitol $(50 \mathrm{mM})$, HEPES (25 mM), EGTA (0.2 mM), potassium cyanide (2 $\mathrm{mM})$ and $1 \% \mathrm{BSA}$ with cell homogenate $(6 \mathrm{mg}$ protein), palmitoyl-CoA $(80 \mu \mathrm{M})$ and carnitine $(1 \mathrm{mM})$. The reaction was started by addition of ${ }^{3} \mathrm{H}$ - carnitine (4.5 $\mu \mathrm{Ci} / \mu \mathrm{mol})$ and terminated by addition of $6 \% \mathrm{HClO}_{4}$. Radioactivity in pamitoyl-carnitine was extracted by butanol and counted in a liquid scintillation counter as described previously [15].
ACC activity was assayed following the method described by Thampy and Wakil [16]. The reaction buffer $(\mathrm{pH} 7.5)$ contained HEPES $(50 \mathrm{mM})$, ATP $(4 \mathrm{mM})$, dithiothreitol (2 mM), $\mathrm{MgCl}_{2}(15 \mathrm{mM})$ and BSA (0.75 mg/ $\mathrm{mL})$ with or without citrate $(15 \mathrm{mM})$. The assay was conducted at $37^{\circ} \mathrm{C}$, initiated by addition of labeled $\mathrm{KHCO}_{3}$ $(12.5 \mathrm{mM})$, and terminated by addition of $50 \mathrm{uL}$ of $\mathrm{HCl}$ $(6 \mathrm{~N})$. Samples $(0.4 \mathrm{~mL})$ were evaporated at $65^{\circ} \mathrm{C}$ under a nitrogen stream and re-suspended in $0.5 \mathrm{~mL}$ of deionized $\mathrm{H}_{2} \mathrm{O}$. The radioactivity in the re-suspended sample was determined via liquid scintillation.

\section{Statistics}

Data were analyzed using the GLM procedure of SAS according to a randomized complete block design [17]. Results were expressed as least-squares means and standard error. Difference of the least-squares means between treatments groups were determined using the Tukey test and considered significantly when $\mathrm{P}<0.05$.

\section{Chemicals}

[1- $\left.{ }^{14} \mathrm{C}\right]$-palmitate, ${ }^{3} \mathrm{H}$-carnitine and $\mathrm{KH}^{14} \mathrm{CO}_{3}$ were purchased from American Radiolabeled Chemicals Inc. (St. Louis, MO). Collagenase was purchased from Life Technologies (Grand Island, NY). All of other chemicals were purchased from Sigma-Aldrich Inc. (St. Louis, MO).

\section{Results}

Fatty-acid-oxidation: Accumulation of ${ }^{14} \mathrm{C}$ in $\mathrm{CO}_{2}$ was decreased by addition of AICAR to hepatocytes isolated from suckled neonatal pigs. ${ }^{14} \mathrm{CO}_{2}$ production in cells incubated with AICAR or AICAR plus insulin was $18 \%$ lower than the control. There was no difference in $\mathrm{CO}_{2}$ production between control and addition of insulin only (Figure 2A). The accumulation of ${ }^{14} \mathrm{C}$ in acid soluble products (ASP) remained relatively consistent for all of four treatments $(P>0.2$; Figure $2 \mathrm{~A})$. No significant differences were observed in total palmitate oxidation $\left(\mathrm{CO}_{2}+\mathrm{ASP}\right)$ among the treatments $(P>0.08$; Figure $2 \mathrm{~A})$. However, addition of AICAR to cells significantly affected the distribution of radioactivity accumulation between $\mathrm{CO}_{2}$ and ASP. The percentage of ${ }^{14} \mathrm{C}$-ASP was increased by $6 \%$ and the percentage of ${ }^{14} \mathrm{CO}_{2}$ was decreased by $26 \%$ compared to control $(P<0.03$; Figure $2 \mathrm{~B})$. Addition of insulin had no influence on the oxidative products distribution $(P>0.05)$.

Enzyme activity: Acetyl-CoA carboxylase activity measured in hepatocyte homogenate was significantly affected by AICAR supplementation (Figure 3). The ACC activity was $45 \%$ higher in hepatocyte incubated with AICAR than in the control $(P<0.02)$. The enzyme activity was $70 \%$ higher in cells incubated with AICAR and insulin than in the control $(P<0.01)$. However, there was no difference between control cells and the 


\section{$\square \mathrm{CO}_{2} \square \mathrm{ASP} \square \mathrm{CO}_{2}+\mathrm{ASP}$}

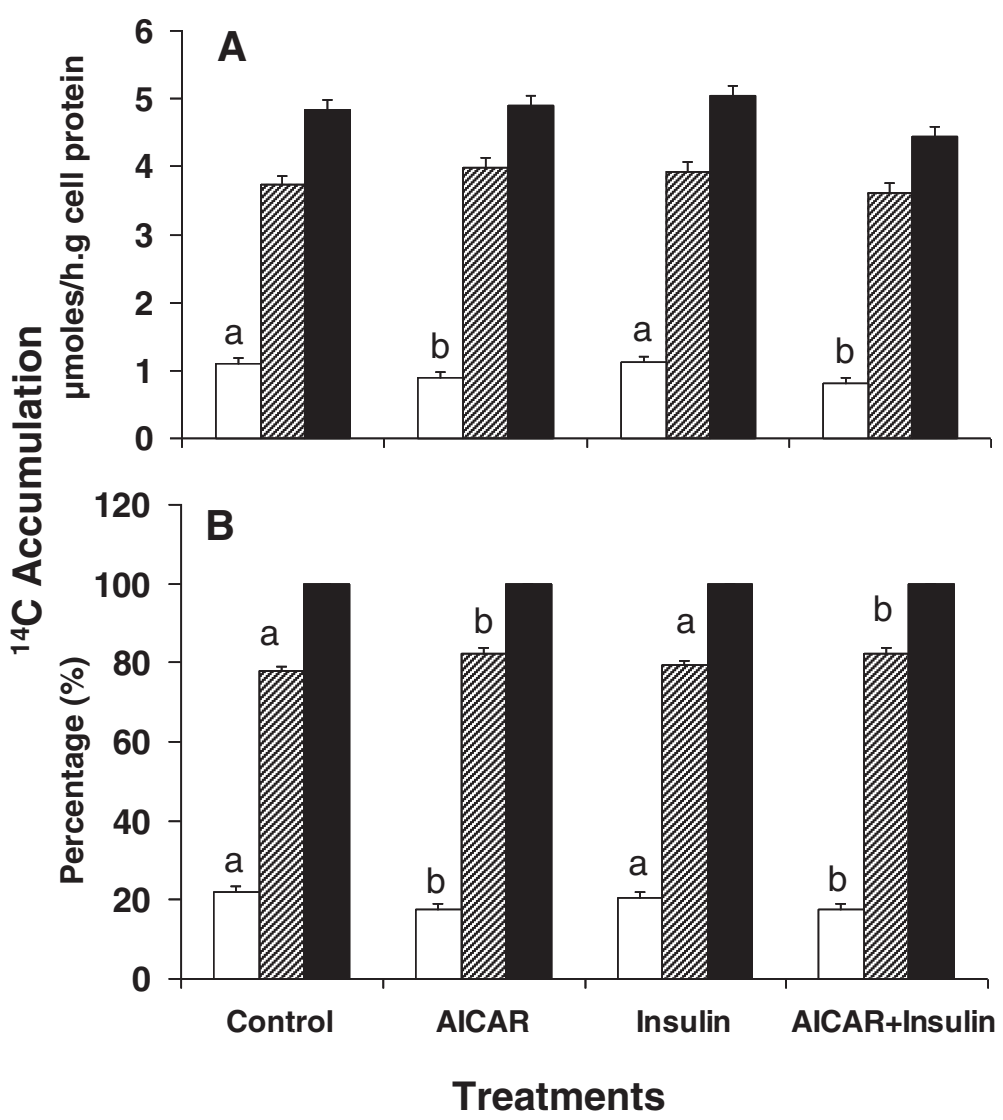

Figure 2 Palmitate oxidation by hepatocyte isolated from suckled neonatal pigs. A. ${ }^{14} \mathrm{C}$ Accumulation in $\mathrm{CO}_{2}$, acid soluble products (ASP) and Total $\left(\mathrm{CO}_{2}+\mathrm{ASP}\right)$. B. percentage of ${ }^{14} \mathrm{C}$ accumulation in $\mathrm{CO}_{2}$ and $\mathrm{ASP}$ based on the total accumulation. Values presented as least-squares means \pm SE. ${ }^{a, b}$ Bars across the treatments with different letters differ $(P<0.05)$.

cells treated with insulin only $(P>0.05)$. Addition of citrate to the cells increased the enzyme activity. The increase was higher in control cells than in the cells

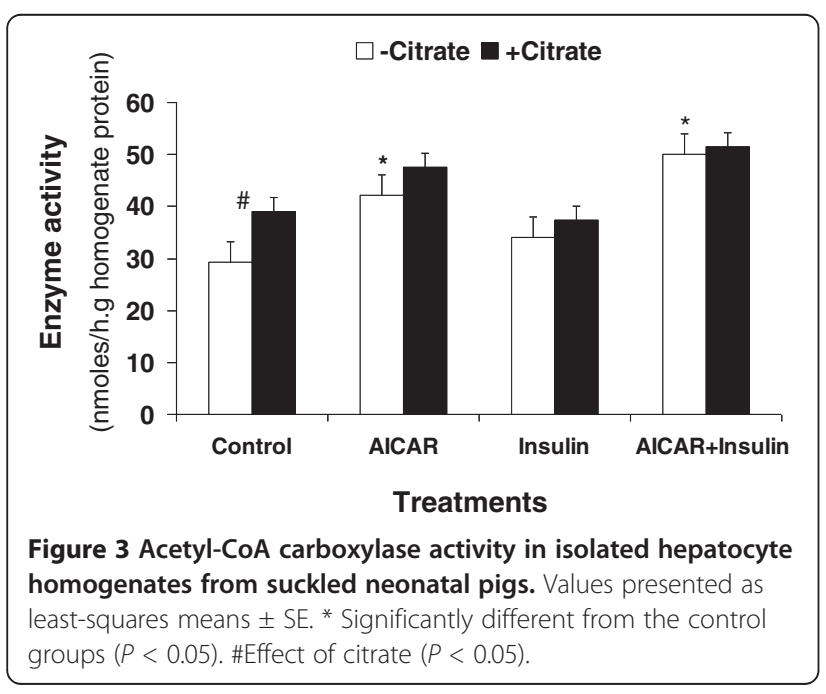

treated with AICAR, insulin or both. Carnitine palmitoyltransferase activity measured in the hepatocyte homogenates (Figure 4) showed no differences among the 4 treatments $(P>0.05)$. Addition of malonyl-CoA to cell homogenates significantly decreased the enzyme activity $(P<0.01)$. The decrease remained constant for all of the treatments.

\section{Discussion}

Evidences from rodent studies have demonstrated that AICAR stimulates fatty acid uptake and fatty acid oxidation in muscle $[10,18,19]$, heart [20] and liver [21]. The stimulation of fatty acid oxidation is recognized as the consequence of phosphorylating and inhibiting ACC, subsequently reducing the concentration of malonyl-CoA, the enzymatic product of $\mathrm{ACC}$ and the physiological inhibitor of CPT I. The reduction of malonyl-CoA concentration reduces CPT I inhibition, and thereby increases the fatty acid oxidation. Indeed, in adult animals it is well established that fatty acid oxidation is controlled mainly by the variation of malonyl-CoA concentration and the sensitivity 


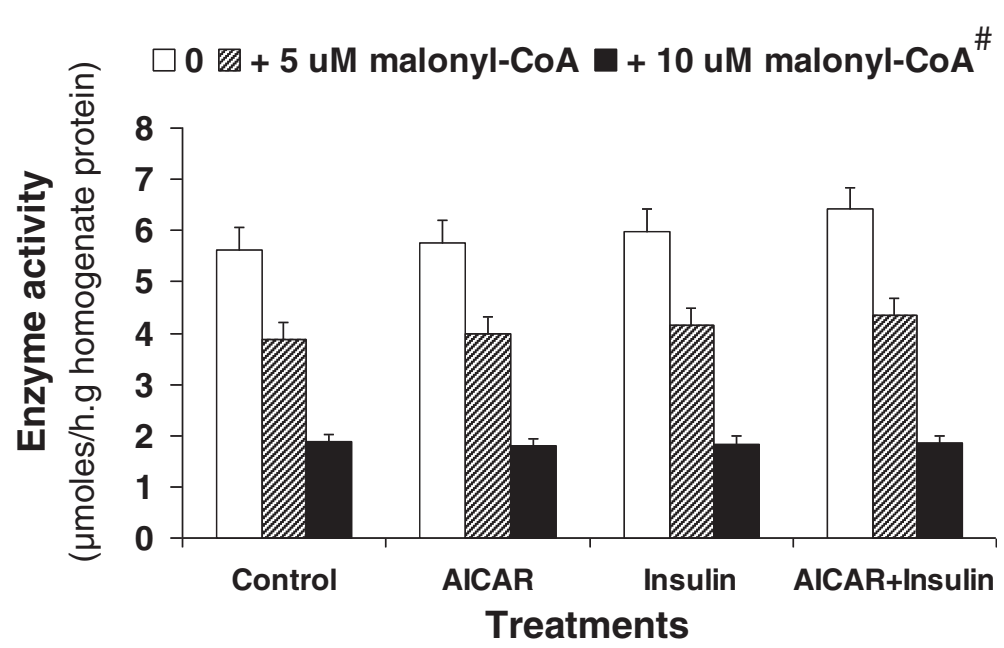

Figure 4 Carnitine palmitoyltransferase activity in isolated hepatocyte homogenates from suckled neonatal pigs. Values presented as least-squares means \pm SE. * Significantly different between with and without malonyl-CoA $(p<0.05)$.

of CPT I to malonyl-CoA inhibition in liver under many physiological conditions. In adult rat hepatocytes, reduction of malonyl-CoA concentration by glucagon significantly increases fatty acid oxidation. However, in this study the concentration of AICAR adapted from rodent species was sufficient to change malonyl-CoA concentrations in rat or mice, but there was no effect on the total $\left[1-{ }^{14} \mathrm{C}\right]$ palmitic acid oxidation in hepatocytes isolated from suckled neonatal piglets. In agreement with the fatty acid oxidation rate, the malonyl-CoA sensitive CPT activity and inhibition of its activity by malonyl-CoA assayed in cell homogenates remained unchanged among the treatments. The dampened responses of fatty acid oxidation to AICAR treatment could be associated with the species differences and the specific physiological status of the hepatocyte at the time of isolation. First, low lipogenesis and limited fatty acid oxidation capacity are observed in hepatocytes isolated from neonatal swine. Results from earlier studies demonstrated that the rate of lipogenesis is very low in isolated hepatocytes from both fed and fasted newborn pigs [22], suggesting that malonyl-CoA concentration could be negligible during early neonatal life. Meanwhile, the oleate oxidation and ketogenesis is about 70 and $80 \%$ lower in mitochondria isolated from newborn piglets than adult rats [1], and more than $90 \%$ of the oleate taken up by the hepatocyte converts to esterified fat [22], suggesting that newborn piglets have a low fatty acid oxidative capacity. However, the extremely low fatty acid oxidation is apparently not due to the CPT I inhibition, because the lipogenesis and malonyl-CoA concentration measured in hepatocytes isolated from newborn piglets is very low $[1,22]$. Therefore, the attenuated response to AICAR might be due to a low baseline concentration malonyl-CoA in the neonatal piglets hepatocytes. Secondly, evidence from literature indicates that the regulation of fatty acid oxidation during the neonatal period is different from adult animals. It is likely that the control of fatty acid oxidation is primarily effected by variation in sensitivity of CPT I to malonyl-CoA inhibition rather than by a change in malonyl-CoA concentration [23]. Indeed, we found that the considerable increase of fatty acid oxidation in hepatic mitochondria isolated from $24 \mathrm{~h}$ old piglets was paralleled with a significantly decrease in sensitivity of CPT I to malonyl-CoA inhibition [4]. Moreover, the decrease in sensitivity of CPT I to malonyl-CoA inhibition was related to the food intake, because the $\mathrm{IC}_{50}$ obtained from $24 \mathrm{~h}$-old fed piglets much higher than that from 24 h-old fasted and newborn piglets [4]. Similar results were also observed in our previous studied using hepatocytes and liver homogenate [2,24]. Because the hepatocytes isolated in this study were from $32 \mathrm{~h}$-old fed piglets, the reduced response to AICAR might also be due an increased $\mathrm{IC}_{50}$ after the piglets suckled. Similar results were observed in muscle isolated from fasted rats [25], suggesting that the stimulation of fatty acid oxidation by AICAR depends on nutritional status. Thus, the stimulation of fatty acid oxidation by AICAR might be limited by the age-related physiological status.

Although AICAR did not change the total fatty acid oxidation, addition of AICAR to the cells decreased $\mathrm{CO}_{2}$ production by $18 \%$, resulting in a significant difference in distribution of oxidative products between $\mathrm{CO}_{2}$ and ASP compared to the control. Consistent with the distribution change, we found that addition of AICAR increased ACC activity in hepatocytes, and the increase was promoted by adding insulin to the cells treated with AICAR. Inclusion of citrate in incubation medium also stimulated ACC activity in the cells, but the stimulation was higher in control cells than in cells treated with AICAR. These results suggest that the increased ACC 
activity induced by AICAR might drive the end product of beta-oxidation, acetyl-CoA, toward fatty acid synthesis, resulting in a decrease of $\mathrm{CO}_{2}$ production from fatty acid oxidation. As already discussed, the nutritional and physiological status of the isolated hepatocytes might be associated with the abrogated response of fatty acid oxidation to AICAR, but we have not evaluated the malonyl-CoA concentrations. If AICAR increases ACC activity, the malonyl-CoA concentration would be increased in the cells. It appeared that the increase of malonyl-CoA did not lead to a change in CPT I activity, the result might imply that the increases did not reach the inhibition level required by the CPT I in the cells with a high $\mathrm{IC}_{50}$ value due to the fed status. Even so, the phenomenon of increasing ACC activity could not be fully explained. Both isomers of $A C C \alpha$ and $A C C \beta$ are expressed in the liver, and $\mathrm{ACC} \alpha$ sustains the regulation of fatty acid synthesis while $A C C \beta$ mainly controls fatty acid oxidation. The assay performed in this study could not distinguish the activity of ACC $\alpha$ and $A C C \beta$, but their expression can be regulated by promoters at the transcriptional level in which nutritional status can play an important role. In addition to regulation at transcriptional level, ACC $\alpha$ and ACC $\beta$ are regulated by phosphorylation and dephosphorylation at the metabolic level. The phosphorylation is due to an increase of AMP levels when the energy status of the cells is low, resulting in the activation of AMPK. The cell energy level was high in this study, but AICAR is an activator of AMPK and its activation is considered to be independent of energy status of the cells [25]. Thus, the opposite influence of AICAR on ACC in newborn suckled pigs needs to be investigated further in both regulatory levels under the specific physiological and nutritional conditions. Particularly, the role of AMPK and insulin in regulation of ACC has not been studied and need to be examined in the neonatal pig. Further investigation is necessary for a better understanding of the energy and metabolic regulation mechanism in the newborn pigs. In summary, AICAR may affect the distribution of metabolic products from fatty acid oxidation in hepatocytes isolated from suckled neonatal pigs by changing ACC activity. The effect of AICAR on ACC activity will be impacted by citrate concentration in the cells.

\footnotetext{
Abbreviations

ASP: Acid Soluble Products; AICAR: 5-Aminoimidazole-4-Carboxamide Ribonucleoside; ACC: Acetyl-CoA Carboxylase; CPT: Carnitine Palmitoyltransferase; AMPK: 5-Adenosine Monophosphate-activated Protein Kinase.
}

\section{Competing interests}

The authors declare that they have no competing interests.

\section{Authors' contributions}

This study was conducted by GM and LX. The experimental design, the data statistical analysis and the manuscript was done by LX. JO participated in the experiment design, co-advised and coordinated the project summaries and publications. All authors read and approved the final manuscript.

\section{Acknowledgements}

This project was supported by National Research Initiative Competitive Grant no. 2007-35206-17897 from the USDA National Institute of Food and Agriculture.

\section{Author details}

${ }^{1}$ Laboratory of Developmental Nutrition, Department of Animal Science, North Carolina State University, Raleigh, NC 27695, USA. ²Gordon Health Center 018, St Augustine's College, 1315 Oakwood Avenue, Raleigh, USA.

Received: 4 May 2012 Accepted: 17 September 2012

Published: 17 October 2012

\section{References}

1. Duée PH, Pégorier JP, Quant PA, Herbin C, Kohl C, Girard J: Hepatic ketogenesis in newborn pigs is limited by low mitochondrial 3-hydroxy3-methylglutaryl-CoA synthase activity. Biochem J 1994, 298(1):207-212.

2. Odle J, Lin X, van Kempen TA, Drackley JK, Adams SH: Carnitine palmitoyltransferase modulation of hepatic fatty acid metabolism and radio-HPLC evidence for low ketogenesis in neonatal pigs. J Nutr 1995, 125(10):2541-2549.

3. Yu XX, Drackley JK, Odle J, Lin X: Response of hepatic mitochondrial and peroxisomal $\beta$-oxidation to increasing palmitate concentrations in piglets. Biol Neonate 1997, 72:284-292.

4. Lin X, Shim K, Odle J: Carnitine palmitoyltransferase I control of acetogenesis, the major pathway of fatty acid \{beta\}-oxidation in live of neonatal swine. Am J Physiol Regul Integr Comp Physiol 2010, 298(5): R1435-R1443.

5. Kim KH: Regulation of mammalian acetyl-coenzyme A carboxylase. Annu Rev Nutr 1997, 17:77-99.

6. Gamble J, Lopaschuk GD: Insulin inhibition of $5^{\prime}$ adenosine monophosphate-activated protein kinase in the heart results in activation of acetyl coenzyme A carboxylase and inhibition of fatty acid oxidation. Metabolism 1997, 46(11):1270-1274

7. Krause $U$, Bertrand L, Hue L: Control of p70 ribosomal protein S6 kinase and acetyl-CoA carboxylase by AMP-activated protein kinase and protein phosphatases in isolated hepatocytes. Eur J Biochem 2002, 269(15):3751-3759.

8. Winder WW, Hardie DG: Inactivation of acetyl-CoA carboxylase and activation of AMP-activated protein kinase in muscle during exercise. Am J Physiol 1996, 270(2 Pt 1):E299-E304.

9. Velasco G, Geelen MJ, Guzmán M: Control of hepatic fatty acid oxidation by $5^{\prime}$-AMP-activated protein kinase involves a malonyl-CoA-dependent and a malonyl-CoA-independent mechanism. Arch Biochem Biophys 1997, 337(2):169-175.

10. Lee WJ, Kim M, Park HS, Kim HS, Jeon MJ, Oh KS, Koh EH, Won JC, Kim MS, Oh GT, Yoon M, Lee KU, Park JY: AMPK activation increases fatty acid oxidation in skeletal muscle by activating PPARalpha and PGC-1. Biochem Biophys Res Commun 2006, 340(1):291-295.

11. Odle J, Benevenga NJ, Crenshaw TD: Postnatal age and the metabolism of medium- and long-chain fatty acids by isolated hepatocytes from smallfor-gestational-age and appropriate-for-gestational-age piglets. J Nutr 1991, 121(5):615-621.

12. Layne E: Spectrophotometric methods for measuring proteins. In Methods in Enzymology III:447. Edited by Colowick SP, Kaplan ND. New York: Academic Press Inc; 1957.

13. Bremer J, Woldegiorgis G, Schalinske K, Shrago E: Carnitine palmitoyltransferase. Activation by palmitoyl-CoA and inactivation by malonyl-CoA. Biochim Biophys Acta 1985, 833(1):9-16.

14. Lin $X$, Odle J: Changes in kinetics of carnitine palmitoyltransferase in liver and skeletal muscle of dogs (Canis familiaris) throughout growth and development. J Nutr 2003, 133(4):1113-1119.

15. Lin X, House R, Odle J: Ontogeny and kinetics of carnitine palmitoyltransferase in liver and skeletal muscle of the domestic felid (Felis domestica). J Nutr Biochem 2005, 6(6):331-338.

16. Thampy KG, Wakil SJ: Activation of acetyl-CoA carboxylase. Purification and properties of a Mn2+-dependent phosphatase. J Biol Chem 1985, 260(10):6318-6323. 
17. SAS: SAS/STAT user's guide (version 6). 4th edition. Cary (NC): SAS Institute; 1989.

18. Smith AC, Bruce CR, Dyck DJ: AMP kinase activation with AICAR further increases fatty acid oxidation and blunts triacylglycerol hydrolysis in contracting rat soleus muscle. J Physiol 2005, 565(Pt 2):547-553.

19. Smith $A C$, Bruce $C R$, Dyck DJ: AMP kinase activation with AICAR simultaneously increases fatty acid and glucose oxidation in resting rat soleus muscle. J Physiol 2005, 565(Pt 2):537-546.

20. Kudo N, Barr AJ, Barr RL, Desai S, Lopaschuk GD: High rates of fatty acid oxidation during reperfusion of ischemic hearts are associated with a decrease in malonyl-CoA levels due to an increase in 5'-AMP-activated protein kinase inhibition of acetyl-CoA carboxylase. J Biol Chem 1995, 270 (29):17513-17520.

21. Ruderman NB, Park H, Kaushik VK, Dean D, Constant S, Prentki M, Saha AK: AMPK as a metabolic switch in rat muscle, liver and adipose tissue after exercise. Acta Physiol Scand 2003, 178(4):435-442.

22. Pégorier JP, Duée PH, Girard J, Peret J: Metabolic fate of non-esterified fatty acids in isolated hepatocytes from newborn and young pigs. Evidence for a limited capacity for oxidation and increased capacity for esterification. Biochem J 1983, 212(1):93-97.

23. Prip-Buus C, Pegorier JP, Duee PH, Kohl C, Girard J: Evidence that the sensitivity of carnitine palmitoyltransferase I to inhibition by malonyl$\mathrm{CoA}$ is an important site of regulation of hepatic fatty acid oxidation in the fetal and newborn rabbit. Perinatal development and effects of pancreatic hormones in cultured rabbit hepatocytes. Biochem J 1990, 269(2):409-415.

24. Yu XX, Drackley JK, Odle J: Food deprivation changes peroxisomal $\beta$-oxidation activity but not catalase activity during postnatal development in pig tissues. J Nutr 1998, 128:1114-1121.

25. Kaushik VK, Young ME, Dean DJ, Kurowski TG, Saha AK, Ruderman NB: Regulation of fatty acid oxidation and glucose metabolism in rat soleus muscle: effects of AICAR. Am J Physiol Endocrinol Metab 2001, 281(2):E335-E340.

doi:10.1186/2049-1891-3-30

Cite this article as: $\mathrm{Xi}$ et al: The effect of 5-aminoimidazole-4carboxamide ribonucleoside (AICAR) on fatty acid oxidation in

hepatocytes isolated from neonatal piglets. Journal of Animal Science and Biotechnology 2012 3:30.

\section{Submit your next manuscript to BioMed Central and take full advantage of:}

- Convenient online submission

- Thorough peer review

- No space constraints or color figure charges

- Immediate publication on acceptance

- Inclusion in PubMed, CAS, Scopus and Google Scholar

- Research which is freely available for redistribution 